\title{
Stage-specific fluorescence intensity of GFP and mCherry during sporulation In Bacillus Subtilis
}

Geoff P Doherty, Kirra Bailey, Peter J Lewis ${ }^{*}$

\begin{abstract}
Background: Fluorescent proteins are powerful molecular biology tools that have been used to study the subcellular dynamics of proteins within live cells for well over a decade. Two fluorescent proteins commonly used to enable dual protein labelling are GFP (green) and mCherry (red). Sporulation in the Gram positive bacterium Bacillus subtilis has been studied for many years as a paradigm for understanding the molecular basis for differential gene expression. As sporulation initiates, cells undergo an asymmetric division leading to differential gene expression in the small prespore and large mother cell compartments. Use of two fluorescent protein reporters permits time resolved examination of differential gene expression either in the same compartments or between compartments. Due to the spectral properties of GFP and mCherry, they are considered an ideal combination for co-localisation and co-expression experiments. They can also be used in combination with fluorescent DNA stains such as DAPI to correlate protein localisation patterns with the developmental stage of sporulation which can be linked to well characterised changes in DNA staining patterns.

Findings: While observing the recruitment of the transcription machinery into the forespore of sporulating Bacillus subtilis, we noticed the occurrence of stage-specific fluorescence intensity differences between GFP and mCherry. During vegetative growth and the initial stages of sporulation, fluorescence from both GFP and mCherry fusions behaved similarly. During stage II-III of sporulation we found that mCherry fluorescence was considerably diminished, whilst GFP signals remained clearly visible. This fluorescence pattern reversed during the final stage of sporulation with strong mCherry and low GFP fluorescence. These trends were observed in reciprocal tagging experiments indicating a direct effect of sporulation on fluorescent protein fluorophores.

Conclusions: Great care should be taken when interpreting the results of protein localisation and quantitative gene expression patterns using fluorescent proteins in experiments involving intracellular physiological change. We believe changes in the subcellular environment of the sporulating cell leads to conditions that differently alter the spectral properties of GFP and mCherry making an accurate interpretation of expression profiles technically challenging.
\end{abstract}

\section{Background}

Various Gram positive bacteria can form structures called endospores, which are highly resistant to environmental stress and can remain dormant for thousands of years. The sporulation process can be crudely divided into five stages; Initiation, septation, engulfment, spore and cortex formation and finally maturation and endospore release (Reviewed in [1]). This process is triggered by a stress response such as starvation and results in the expression and repression of a cascade of genes in a

\footnotetext{
* Correspondence: Peter.Lewis@newcastle.edu.au

School of Environmental and Life Sciences, University of Newcastle, Callaghan, NSW 2308, Australia
}

tightly controlled temporal manner over several hours in order to form the mature endospore as outlined in Figure 1. After the decision to sporulate has occurred, the rod-shaped cell asymmetrically divides to form a prespore and a much larger mother cell. The mother cell then engulfs the prespore, after which the cortex and the spore coat form. Finally, the mother cell undergoes programmed cell death and the mature endospore is released. This entire process has served as a paradigm for gene regulation and expression and has been extensively studied for over two decades.

We decided to study the recruitment of the transcriptional machinery into the spore during this process 


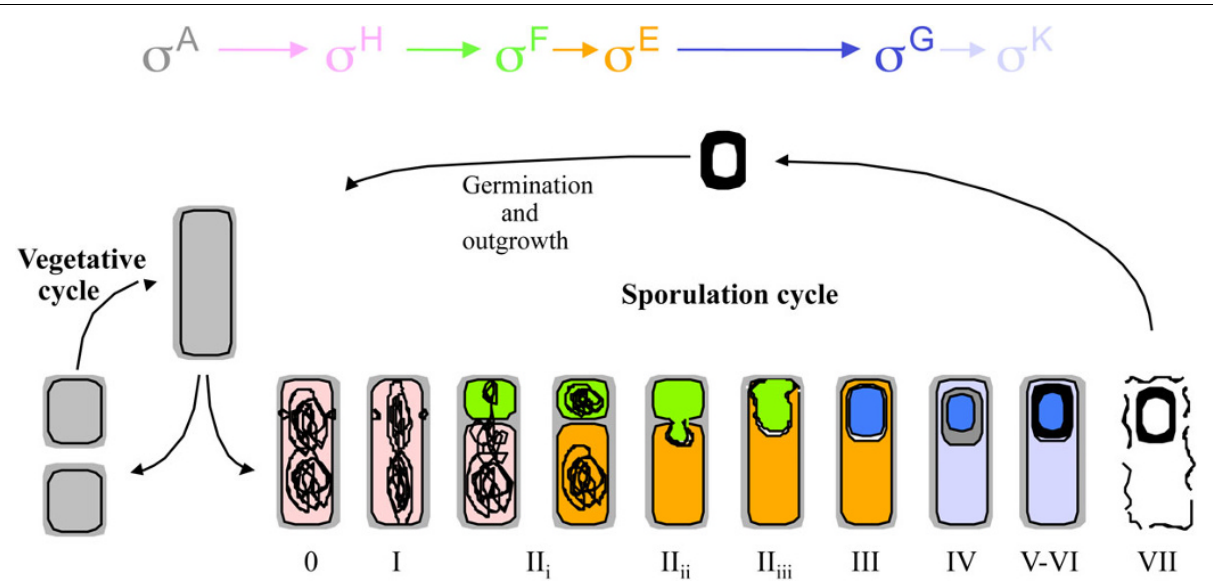

Figure 1 Schematic of sporulation. Overview of the sporulation cycle. When vegetative cells encounter conditions of stress such as starvation the sporulation cycle is induced. Division of the vegetative cell occurs asymmetrically forming the mother cell and pre-spore, both containing a copy of the genome. Engulfment of the prespore occurs before the spore coat and cortex are laid down. Eventually the mother cell lyses to release the mature spore. Gene expression is controlled temporally by a subset of sigma factors in both the developing spore and mother cell. The location and time of sigma factor involvement is colour coded in this schematic.

using both GFPmut3 and mCherry. The spectral properties of these proteins allows the study of two proteins within the same cell with very little crossover into the other channel $[2,3]$. During these studies we noticed a trend in fluorescence that was attributable to the fluorescent protein rather than the protein of interest. In this work we present data on the changes in fluorescence emission of GFP and mCherry during the sporulation process, which has wide ramifications on both past and future studies of gene expression and regulation during the sporulation process in B. subtilis.

\section{Materials and methods}

Strain construction growth conditions and image analysis All plasmids and strains used in this work are detailed in Table 1. GFP cloning was performed by ligation independent cloning (LIC) as detailed in [4] using primers in Table 2. The $m$ Cherry gene fusions were created by PCR amplifying the 3' end of the respective genes using primers in Table 2, and digesting them with the appropriate restriction enzymes, before ligating them into similarly cut pNG621. Transformation of B. subtilis was carried out as per [5]. B. subtilis cells were induced to sporulate by the resuspension method of [6] as modified by [7]. Image acquisition and analysis was performed as described by [8].

\section{Overproduction and purification of GFP and mCherry}

GFPmut3 was overproduced and purified as detailed in [8]. The gene encoding $m$ Cherry was PCR amplified off pNG621 using pETmCherryF and pETmCherryR (Table 2) and cloned into pETMCSIII using NdeI and EcoRI to give rise to pNG735 (Table 1). Overproduction, purification and quantification of the purified mCherry protein was carried out as per GFPmut3 as detailed in [8].

\section{Determining the pH-dependent emission of GFP and mCherry}

The $\mathrm{pH}$ of potassium phosphate buffers $(20 \mathrm{mM}$ $\mathrm{KH}_{2} \mathrm{PO}_{4}, 200 \mathrm{mM} \mathrm{NaCl}, 10 \%$ glycerol) were adjusted using either $5 \mathrm{M} \mathrm{KOH}$ or $5 \mathrm{M} \mathrm{HCl}$ to yield twelve buffers with a $\mathrm{pH}$ of 4.4, 5.0, 5.5, 6.0, 6.5, 7.0, 7.5, 7.75, 8.0, 8.25, 8.5 and 9.1. Purified GFPmut3 and mCherry were both added to a final concentration of $1 \mu \mathrm{M}$ in each of the buffers. $100 \mu \mathrm{l}$ aliquots of these were then transferred to a 96 well microplate (NUNC), and then placed in a FLUOROstar Optima (BMG LabTech) where the GFP (excitation $480 / 10 \mathrm{~nm}$; emission $520 / 10 \mathrm{~nm}$ ) and mCherry (excitation $570 / 10 \mathrm{~nm}$; emission $620 / 10 \mathrm{~nm}$ ) signals were read before being processed in Microsoft Excel.

\section{Results and Discussion}

In this work we set out to study the recruitment of transcriptional machinery into the spore during sporulation using mCherry labelled RNA polymerase (RNAP; inframe fusion to the $\beta$ ' subunit, Table 1) and GFP labelled transcription factor NusA, along with small auxiliary RNAP subunits $\delta, \omega$ and YkzG (Table 1). A trend was noticed that showed very little RNAP-mCherry fluorescence, but a high amount of GFP fluorescence of tagged NusA during stages III to V (refer to Figure 1) of sporulation. This was followed by a complete reversal of fluorescence in the final stages when the spore became phase bright, with high RNAP-mCherry, and almost undetectable NusA-GFP signals. Similar results were obtained when co-localising mCherry labelled 
Table 1 Plasmids and strains used in this work

\begin{tabular}{|c|c|c|}
\hline Plasmid & Genotype & Source/Construction \\
\hline pYG1 & $P_{\text {spac }}$-LIC-gfpmut3-erm & {$[8]$} \\
\hline pEU2 & $P_{\text {spac }}$-'rpoB-gfpmut3-erm & This work \\
\hline pETMCSIII & bla $P_{\text {spac }}-10-6 H i s T \phi$ & {$[17]$} \\
\hline pEU13 & $P_{\text {spac }}$-'yloH-gfpmut3-erm & This work \\
\hline pEU14 & $P_{\text {spac }}-y k z$ 'y-gfpmut3-erm & [8] \\
\hline pEU16 & $P_{\text {spac }}$-'rpoE-gfpmut3-erm & {$[8]$} \\
\hline pEU21 & $P_{\text {spac }}{ }^{-}$rpoC-gfpmut3-erm & {$[8]$} \\
\hline pEU37 & $P_{\text {spac }}$-'nusA-gfpmut3-erm & This work \\
\hline pNG583 & bla $P_{\text {spac }}-10$-gfpmut3-6HisT $\phi$ & [8] \\
\hline pNG621 & $P_{x y l}$-MCS-mCherry-cat & {$[8]$} \\
\hline pNG622 & $P_{x y I^{\prime}-r p o C-m C h e r r y-c a t}$ & {$[8]$} \\
\hline pNG670 & $P_{x y l}$-'nusA-mCherry-cat & This work \\
\hline pNG677 & $P_{x y l}-y_{k z G-m C h e r r y-c a t}$ & This work \\
\hline pNG735 & bla $P_{\text {spac }}-10-m$ Cherry-6HisT $\phi$ & This work \\
\hline Strain & Genotype & Source/Construction \\
\hline \multicolumn{3}{|l|}{ E. coli } \\
\hline $\begin{array}{l}\text { BL21(DE3) } \\
\text { pLysS }\end{array}$ & $\lambda$ DE3 pLysS; F-ompT\{lon\}hsdSB (rB-mB-) & {$[18]$} \\
\hline $\mathrm{DH} 5 \alpha$ & $\begin{array}{l}\text { F- endAl hsdR17 supE44 thi-1 } \lambda \text { - recAl gyrA96 relA1 } \triangle \text { (lacZY A-argF) U169 } \Phi 80 \text { dlacZ } \\
\text { 4u15 }\end{array}$ & Gibco BRL \\
\hline \multicolumn{3}{|l|}{ B. subtilis } \\
\hline $168 \operatorname{trp}+$ & $\operatorname{trpC2}$ chr::trp & [4] \\
\hline EU1 & 168trp+chr:: erm $P_{w t} r p o B-g f p, P_{\text {spac }}{ }^{\prime} r p o B$ & This work: 168trp+ transformed with pEU2 \\
\hline EU16 & 168trp+chr:: erm $P_{w t} y l o H$-gfp, $P_{\text {spac }}$ 'yloH & This work: 168trp+ transformed with pEU13 \\
\hline$\underline{\text { EU17 }}$ & 168trp+ chr:: erm $P_{w t} y k z G-g f p P_{\text {spac }} y k z G$ & This work: 168trp+ transformed with pEU14 \\
\hline EU19 & 168trp+chr:: erm $P_{w t} r p o E-g f p, P_{\text {spac }}{ }^{\prime} r p o E$ & This work: 168 trp+ transformed with pEU16 \\
\hline EU44 & 168trp+ chr:: erm $P_{w t} r p o C-g f p, P_{\text {spac }}$ 'rpoC & [8] \\
\hline EU49 & 168trp+ chr:: erm $P_{w t}$ nusA-gfp, $P_{x y l}$ 'nusA & This work: 168trp+ transformed with pEU37 \\
\hline EU128 & 168trp+ chr:: erm $P_{w t} r p o C-m C h e r r r y, P_{x y l}{ }^{\prime} r p o C$ & $\begin{array}{l}\text { This work: 168trp+ transformed with } \\
\text { pNG621 }\end{array}$ \\
\hline EU131 & 168trp+ chr:: erm $P_{w t} y k z G-m C h e r r r y, P_{x y l}{ }^{\prime} y k z G$ & $\begin{array}{l}\text { This work: 168trp+ transformed with } \\
\text { pNG677 }\end{array}$ \\
\hline EU142 & 168trp+ chr:: erm $P_{w t}$ nusA-mCherrry, $P_{x y l}$ 'nusA & $\begin{array}{l}\text { This work: 168trp+ transformed with } \\
\text { pNG670 }\end{array}$ \\
\hline EU156 & 168trp+ chr:: cat $P_{w t} r p o C-m C h e r r r y, P_{x y l}$ 'rpoC, erm $P_{w t} r p o B$-gfp, $P_{\text {spac }}{ }^{\prime} r p o B$ & This work: EU126 transformed with pEU2 \\
\hline EU163 & 168trp+ chr:: cat $P_{w t} r p o C-m C h e r r r y, P_{x y l}{ }^{\prime} r p o C$, erm $P_{w t} y l o H-g f p, P_{\text {spac }}$ 'yloH & This work: EU126 transformed with pEU13 \\
\hline EU164 & 168trp+ chr:: cat $P_{w t} r p o C-m C h e r r r y, P_{x y l} ' r p o C$, erm $P_{w t} y k z G-g f p, P_{\text {spac }} y k z G$ & This work: EU126 transformed with pEU14 \\
\hline EU166 & 168trp+ chr:: cat $P_{w t} r p o C-m C h e r r r y, P_{x y l}{ }^{\prime} r p o C$, erm $P_{w t} r p o E-g f p, P_{\text {spac }}{ }^{\prime} r p o E$ & This work: EU126 transformed with pEU16 \\
\hline EU183 & 168trp+ chr:: cat $P_{w t}$ rpoC-mCherrry, $P_{x y l}$ 'rpoC, erm $P_{w t}$ nusA-gfp, $P_{\text {spac }}$ 'nusA & This work: EU126 transformed with pEU37 \\
\hline EU186 & 168trp+chr:: cat $P_{w t}$ nusA-mCherrry, $P_{x y l}$ 'nusA, erm $P_{w t}$ ykzG-gfp, $P_{\text {spac }}$ 'ykzG & This work: EU142 transformed with pEU14 \\
\hline EU224 & 168trp+ chr:: cat $P_{w t}$ ykzG-mCherrry, $P_{x y l}$ 'ykzG, erm $P_{w t}$ nusA-gfp, $P_{\text {spac }}$ 'nusA & This work: EU131 transformed with pEU37 \\
\hline EU230 & 168trp+ chr:: cat $P_{w t}$ ykzG-mCherrry, $P_{x y l}$ 'ykzG, erm $P_{w t} r p o C-g f p, P_{\text {spac }}$ 'rpoC & This work: EU131 transformed with pEU21 \\
\hline
\end{tabular}

RNAP ( $\beta$ ' subunit) with GFP tagged RpoE (RNAP $\delta$ subunit), YloH (RNAP $\alpha$ subunit) and YkzG (uncharacterised RNAP subunit).

To further investigate this, we labelled RNAP with both mCherry and GFP to determine if the spectral properties of GFP and mCherry were affected at the different stages of sporulation. Prokaryotic RNAPs are highly conserved comprising four essential subunits; two $\alpha$ subunits, a $\beta$ and a $\beta$ '. We created EU156 (Table 1), which is a strain containing a GFP fusion to the $\beta$ 
Table 2 Primers used in this work

\begin{tabular}{|c|c|}
\hline Plasmid & Primer Sequence $\left(5^{\prime}-3^{\prime}\right)$ \\
\hline$\overline{p E U 2}$ & $\begin{array}{l}\text { rpoB F GGGTTCCTGGCGCGAGCGCAGCAGCCTCTTGGCGGTAAAGCGCAATTTGG } \\
\text { rpoB R TTGGGCTGGCGCGAGCTTCTTTTGTACTACATCGCGTTCAACGTCTGC }\end{array}$ \\
\hline pEU13 & $\begin{array}{l}\text { YloH F GGGTTCCTGGCGCGAGCTTAGATCCGTCAATTGATTCTTTAATG } \\
\text { YloH R TTGGGCTGGCGCGAGCTTCGCGGTCTTCCTITCAAACG }\end{array}$ \\
\hline pEU14 & $\begin{array}{l}\text { YkzG F GGGTTCCTGGCGCGAGCATTTATAAGGTATTTATCAAGAGAAGGCTG } \\
\text { YkzG R TTGGGCTGGCGCGAGCTAACTCCAATACTTAAAATITCGCTCTG }\end{array}$ \\
\hline pEU16 & $\begin{array}{l}\text { RpoE F GGGTTCCTGGCGCGAGCCGCATCTTTGCTCGGCGTG } \\
\text { RpoE R TTGGGCTGGCGCGAGCTTIAATTCCTCTTCTTCATCATCATAGTC }\end{array}$ \\
\hline pEU21 & $\begin{array}{l}\text { RpoC F GGGTTCCTGGCGCGAGCCGTAGAAGTAATGGTTCGCCAG } \\
\text { RpoC R TTGGGCTGGCGCGAGCTTCAACCGGGACCATATCGTC }\end{array}$ \\
\hline pEU37 & $\begin{array}{l}\text { NusA F GGGTTCCTGGCGCGAGCCACAGATGATCCTGACGTTGATC } \\
\text { NusA R TTGGGCTGGCGCGAGCTTCATCCGATCAGCAGTTTCAGG }\end{array}$ \\
\hline pNG670 & $\begin{array}{l}\text { NusA mCherry F AAGGGGGGAGACCTCGAGATGAGCAGTGAA (Xhol) } \\
\text { NusA mCherry R ACCTAAAGTCACGAATTCTCATCCGATTC (ECORI) }\end{array}$ \\
\hline pNG677 & $\begin{array}{l}\text { YkzG mCherry F AGATTTGGTACCATTTATAAGGT (Acc651) } \\
\text { YkzG mCherry R TCATACDTCGAGTAACTCCAATA (Xhol) }\end{array}$ \\
\hline pNG735 & $\begin{array}{l}\text { pETmCherry F TाTाTCATATGGTGAGCAAGGGCGAGG (Ndel) } \\
\text { pETmCherry R TाTाTGAATTCCTACTTGTACAGCTCGTCC (ECoRl) }\end{array}$ \\
\hline
\end{tabular}

Restriction sites underlined

subunit and an mCherry fusion to the $\beta$ ' subunit and observed the localisation patterns during sporulation. Results are presented in Figure 2, showing phase contrast (top panels), DNA (blue), $\beta$ '-mCherry (red), $\beta$-GFP (green), an image overlay of the $\beta^{\prime}$-mCherry and $\beta$-GFP signals and a linescan taken through the image overlay. Images were taken every two hours from vegetative growth (T0) through to stage V-VI of sporulation (T6).

It is clear from the linescan during vegetative growth that the fluorescence of both $\beta$-GFP and $\beta$ '-mCherry are equal and consistent with what would be expected when subunits of equal stoichiometry are labelled (Figure 2F). Because the sporulating culture was asynchronous and not all cells go on to sporulate, the T2 images show cells that are stage 0 or I (the two cells on the left), and those in stage II (the two cells on the right). Although the GFP and mCherry fluorescence is quite similar between cells at $\mathrm{T} 2$, a slight drop in mCherry fluorescence can be seen in one of the developing forespores (arrows in Figure 2I-L), which by reference to the DAPI stained DNA image (Figure $2 \mathrm{H}$ ), looks to be at a later part of stage $\mathrm{II}$ than the left cell (stage $\mathrm{II}_{\mathrm{ii}} v s \mathrm{II}_{\mathrm{i}}$; Figure 1). By T4 there is a dramatic difference in fluorescence between GFP and mCherry, with almost no detectable mCherry in the developing spore, and bright GFP fluorescence (arrows in Figure 2O-R). At T6 when sporulation reaches stage V-VI and developing spores become phase bright, there is a complete reversal of this fluorescence pattern. The fluorescence from the $\beta$-GFP becomes almost undetectable, while the fluorescence from $\beta$ '-mCherry returns to levels similar to that seen in the mother cell (arrows in Figure 2U-X). Interestingly, due to the asynchrony of sporulation, there is a cell in this micrograph still with a phase dark spore (indicated by the asterisks) and fluoresces similar to that described for cells at stage III-IV seen in T4 cultures.

The pattern of fluorescence described above was also observed for $\beta$ '-mCherry with GFP labelled NusA, $\omega, \delta$ and YkzG, as well as YkzG-mCherry/NusA-GFP, YkzGmCherry/ $\beta$ '-GFP and NusA-mCherry/YkzG-GFP pairs (Table 1; data not shown). Regardless of the protein of interest, GFP always fluoresced brighter during the initial stages of sporulation before dropping off in phase bright spores, while mCherry always fluoresced less brightly in the initial stages before fluorescing brightly in phase bright spores. Fluorescence microscopy was performed on the wild-type parent strain 168trp+ at the same time as the fluorescent protein data using identical image acquisition and processing settings. Results indicated there was virtually no auto-fluorescence using our GFP and mCherry filters that could account for this phenomenon (Figure 3).

It was previously shown that $\mathrm{pH}$ fluctuations occur during sporulation of yeast and Bacillus $s p$. with vegetative cells and the mother cell generally having a $\mathrm{pH}$ of around 8 , while the dormant spore has a $\mathrm{pH}$ of around 6 [9-11]. A study monitoring the internal $\mathrm{pH}$ changes during sporulation of $B$. megaterium has shown that the $\mathrm{pH}$ in the spore remains constant for the first four hours, probably to around late stage III or stage IV, before rapidly dropping over the following two hours [11]. To investigate whether local changes in $\mathrm{pH}$ during sporulation could account for the altered intensity profiles of GFP and mCherry, the $\mathrm{pH}$-dependent emission profiles of these fluorescent proteins were determined and are shown in Figure 4. These profiles suggest that 


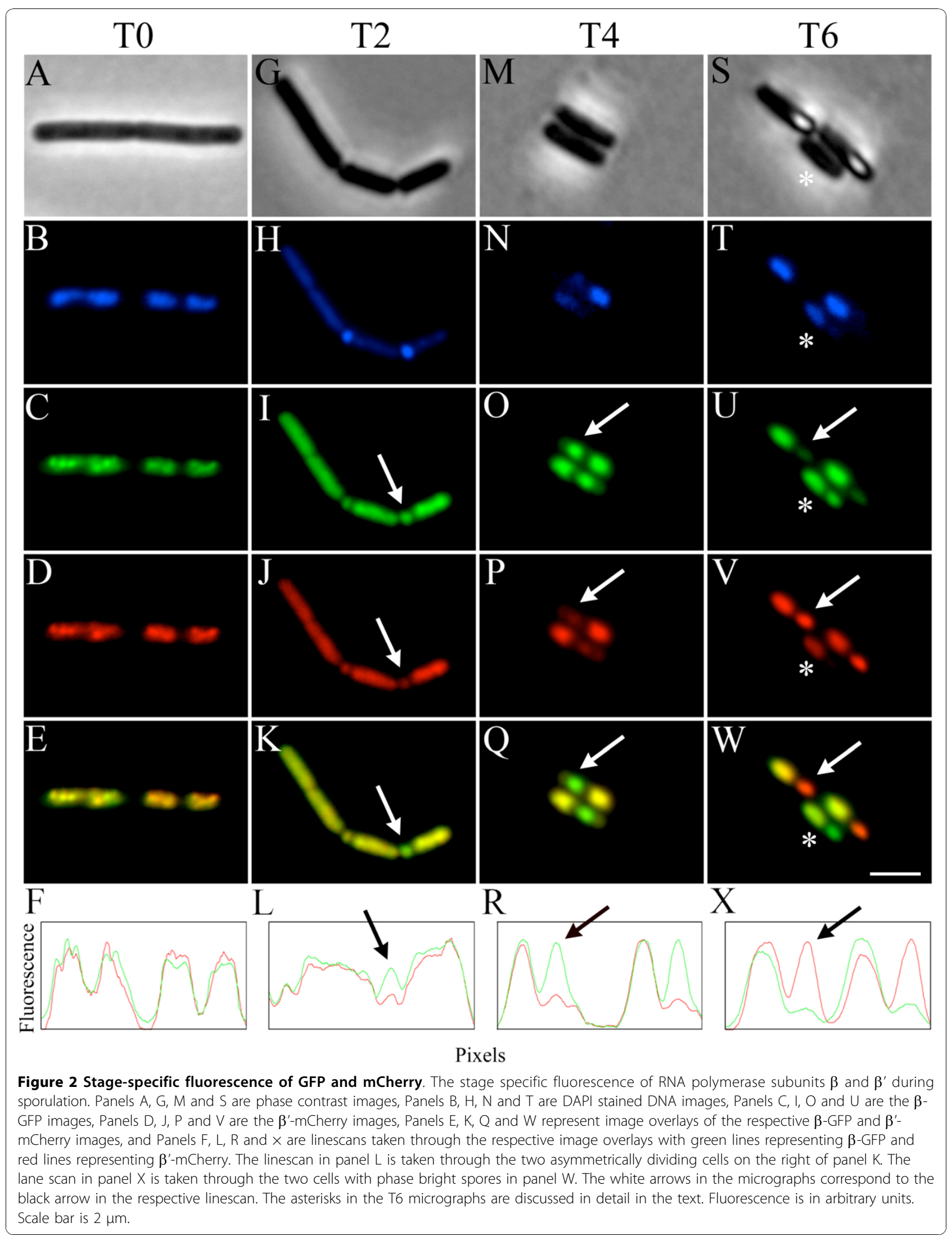




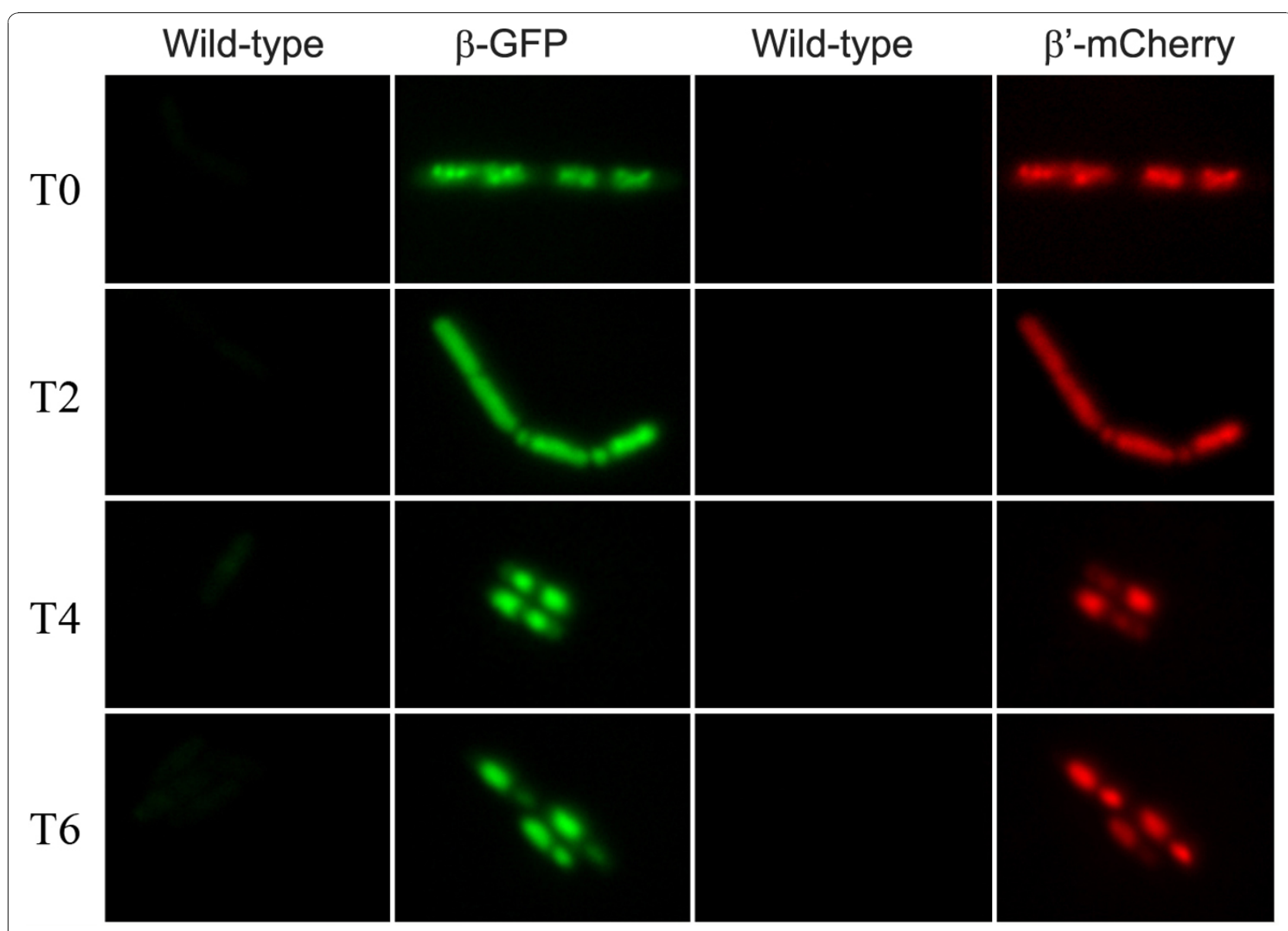

Figure 3 Autofluorescence during spourulation. Autofluorescence is very low during sporulation. Fluorescence emission signals for wild type (left) and fluorescent fusion strains (right) are shown for the GFP and mCherry channels at the time (hours) after resuspension into sporulation medium. The images have been equalised so that the fluorescence through the GFP channels is identical for the wild type and fluorescent fusion strain, and likewise in the mCherry channel. The cells for the GFP and mCherry fluorescent fusions are the same as those shown in Figure 2 for reference.

the fluorophore of mCherry is more tolerant to a drop in $\mathrm{pH}$ when compared to GFP. Indeed an internal $\mathrm{pH}$ of below 6.5 in the phase bright spore could very well explain the fluorescence pattern seen in Figure 2 for phase bright spores (Figure 2S-X). However, nowhere in the intensity profile is there a $\mathrm{pH}$ where the mCherry emission is adversely effected while GFP emission is unaffected.

Both GFPmut3 and mCherry have similar maturation times (around 30 minutes for GFPmut3 [2] and between 15 and 40 minutes reported for mCherry [12,13], so a slower maturation time of mCherry is unlikely to explain the reduced fluorescence observed during the early stages of sporulation. One of the major differences in the maturation process is the need for two moles of molecular oxygen to form a mature mCherry chromophore, compared to the one mole required for GFP [3,14]. It is feasible that a reduction in oxygen availability could account for these emission differences during sporulation, although it was recently found that mCherry maturation was unimpeded under hypoxic conditions when expressed in Mycobacterium tuberculosis [15].

We believe the results presented here have far reaching implications on the use of fluorescent proteins to quantitatively study gene regulation during live cell imaging involving intracellular physiological changes, or even between intracellular compartments in 'steady state' eukaryotic cells. Indeed a very recent publication on gene expression using GFP and mCherry reporter fusions appeared to identify exactly this phenomenon. The expression of kinA, an important kinase involved in the phosphorelay pathway during sporulation was found to be expressed much earlier, with a larger peak when the $k i n A$ promoter was fused to $g f p$ when compared to the promoter fusion to $m$ Cherry [16]. The authors suggested this could be due to a slower maturation time of mCherry compared to GFP, however, as mentioned above the documented maturation times for these 


\section{Fluorescence Intensity vs $\mathrm{pH}$}

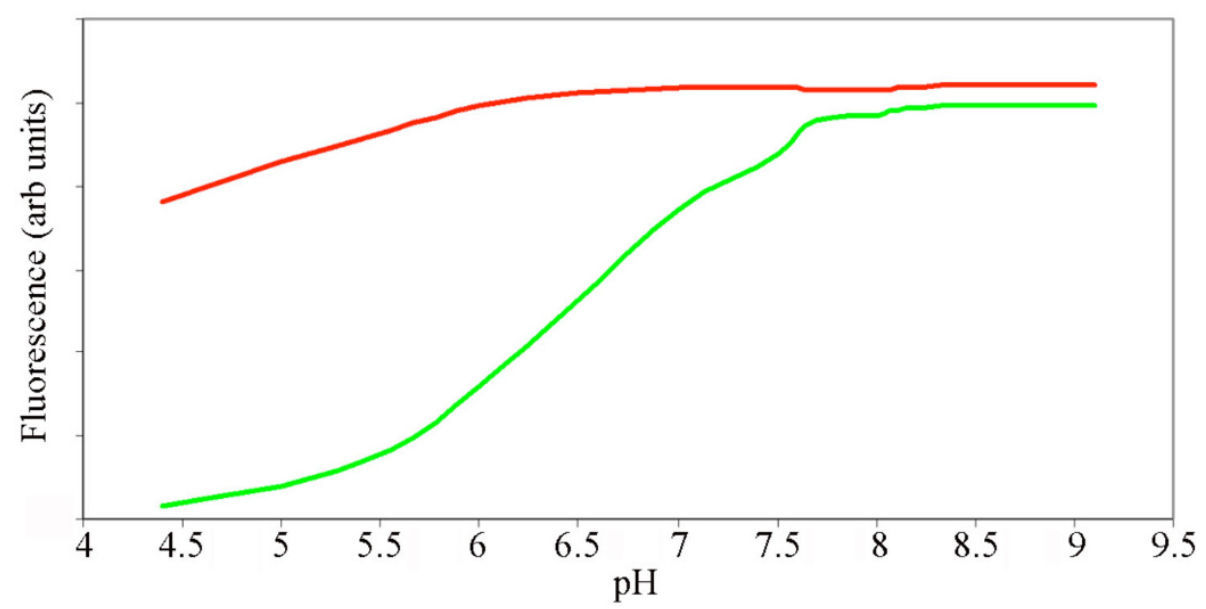

Figure 4 The pH-dependent emission profile of GFP and mCherry. GFP is more sensitive to $\mathrm{pH}$ change than mCherry. The $\mathrm{pH}$-dependent emission profile of GFP and mCherry was investigated by resuspending GFP and mCherry in phosphate buffers with a pH ranging from 4.4 to 9.1. The emission was then plotted against the $\mathrm{pH}$ value to obtain the profile.

fluorescent proteins are similar, and is therefore unlikely to explain the results observed during that work.

In summary, we have identified artefacts that may arise when quantitatively using GFP and mCherry during sporulation. It appears that the emission profile of GFP is not substantially affected during early sporulation, and is probably the most effective fluorescent protein for this phase in sporulation before the $\mathrm{pH}$ drops at around stage IV-V of sporulation. Conversely, this period appears to adversely affect mCherry emission, but it recovers in the final stages of sporulation. Considering sporulation is a paradigm in which to study gene regulation and expression, we urge caution when interpreting fluorescent protein reporter results. As Remington pointed out in a review in 2007, "the lack of understanding of the maturation, photochemistry and photophysics of fluorescent proteins can lead to significant pitfalls in everyday applications" [14].

\section{Acknowledgements}

The work presented in this publication was supported by funding through the NHMRC grant $455646(\mathrm{PL})$ and EU $6^{\text {th }}$ framework grant LSHG-CT-2006037469 (PL).

\section{Authors' contributions}

$\mathrm{PL}$ and $\mathrm{GD}$ designed experiments. GD and KB performed experiments. GD and PL interpreted results and prepared manuscript for publication. All authors read and approved the final draft.

\section{Competing interests}

The authors declare that they have no competing interests.

Received: 19 August 2010 Accepted: 14 November 2010 Published: 14 November 2010

\section{References}

1. Errington J: From spores to antibiotics via the cell cycle. Microbiology 2010, 156:1-13.

2. Cormack BP, Valdivia RH, Falkow S: FACS-optimized mutants of the green fluorescent protein (GFP). Gene 1996, 173:33-38.

3. Shu X, Shaner NC, Yarbrough CA, Tsien RY, Remington SJ: Novel chromophores and buried charges control color in mFruits. Biochemistry 2006, 45:9639-9647.

4. Botella E, Fogg MJ, Jules M, Piersma S, Doherty GP, Hansen A, Denham EL, Le Chat L, Veiga P, Bailey K, Lewis PJ, van Dij JM, Aymerich S, Wilkinson AJ, Devine KM: pBaSysBioll: an integrative plasmid generating gfp transcriptional fusions for high-throughput analysis of gene expression in Bacillus subtilis. Microbiology 2010, 156:1600-1608.

5. Kunst F, Rapoport $G$ : Salt stress is an environmental signal affecting degradative enzyme synthesis in Bacillus subtilis. J Bacteriol 1995, 177:2403-2407.

6. Sterlini JM, Mandelstam J: Commitment to sporulation in Bacillus subtilis and its relationship to development of actinomycin resistance. Biochem J 1969, 113:29-37.

7. Partridge SR, Errington J: The importance of morphological events and intercellular interactions in the regulation of prespore-specific gene expression during sporulation in Bacillus subtilis. Mol Microbiol 1993, 8:945-955.

8. Doherty GP, Fogg MJ, Wilkinson AJ, Lewis PJ: Small subunits of RNA polymerase: localisation, levels and implications for core enzyme composition. Microbiology 2010, 156:3532-3543.

9. Barton JK, den Hollander JA, Lee TM, MacLaughlin A, Shulman RG: Measurement of the internal $\mathrm{pH}$ of yeast spores by 31P nuclear magnetic resonance. Proc Natl Acad Sci USA 1980, 77:2470-2473.

10. Setlow B, Setlow P: Measurement of the $\mathrm{pH}$ within dormant and germinated bacterial spores. Proc Natl Acad Sci USA 1980, 77:2474-2476.

11. Magill NG, Cowan AE, Koppel DE, Setlow P: The internal pH of the forespore compartment of Bacillus megaterium decreases by about 1 pH unit during sporulation. J Bacteriol 1994, 176:2252-2258.

12. Shaner NC, Steinbach PA, Tsien RY: A guide to choosing fluorescent proteins. Nature Methods 2005, 2:905-909.

13. Merzlyak EM, Goedhart J, Shcherbo D, Bulina ME, Shcheglov AS, Fradkov AF, Gaintzeva A, Lukyanov KA, Lukyanov S, Gadella TW, Chudakov DM: Bright monomeric red fluorescent protein with an extended fluorescence lifetime. Nat Methods 2007, 4:555-557. 
14. Remington SJ: Fluorescent proteins: maturation, photochemistry and Photophysics. Curr Opin Struct Biol 2006, 16:714-721.

15. Carroll P, Schreuder LJ, Muwanguzi-Karugaba J, Wiles S, Robertson BD, Ripoll J, Ward TH, Bancroft GJ, Schaible UE, Parish T: Sensitive detection of gene expression in mycobacteria under replicating and non-replicating conditions using optimized far-red reporters. PLoS One 2010, 5:e9823.

16. de Jong IG, Veening JW, Kuipers OP: Heterochronic phosphorelay gene expression as a source of heterogeneity in Bacillus subtilis spore formation. J Bacteriol 2010, 192:2053-2067.

17. Neylon C, Brown SE, Kralicek AV, Hill TM, Dixon NE: Interaction of the Escherichia coli replication terminator protein (Tus) with DNA: a model derived from DNA-binding studies of mutant proteins by surface plasmon resonance. Biochemistry 2000, 39:11989-11999.

18. Studier FW, Moffatt BA: Use of bacteriophage T7 RNA polymerase to direct selective high-level expression of cloned genes. J Mol Biol 1986, 189:113-130.

doi:10.1186/1756-0500-3-303

Cite this article as: Doherty et al: Stage-specific fluorescence intensity of GFP and mCherry during sporulation In Bacillus Subtilis. BMC Research Notes 2010 3:303.

\section{Submit your next manuscript to BioMed Central} and take full advantage of:

- Convenient online submission

- Thorough peer review

- No space constraints or color figure charges

- Immediate publication on acceptance

- Inclusion in PubMed, CAS, Scopus and Google Scholar

- Research which is freely available for redistribution

Submit your manuscript at www.biomedcentral.com/submit 